\title{
Downregulation of cyclooxygenase-1 stimulates mitochondrial apoptosis through the NF-kB signaling pathway in colorectal cancer cells
}

\author{
LEI DING ${ }^{1-3^{*}}$, HUAN GU $^{1,2^{*}}$, ZHENWEI LAN ${ }^{1,2^{*}}$, QINGCHUN LEI $^{4}$, WENXUE WANG $^{1,2}$, \\ JIANGFEI RUAN ${ }^{1,2}$, MIN YU $^{1-3}$, JIE LIN $^{2}$ and QINGHUA CUI ${ }^{1-3}$ \\ ${ }^{1}$ Laboratory of Biochemistry and Molecular Biology, School of Life Sciences, Yunnan University; \\ ${ }^{2}$ Key Laboratory of Molecular Cancer Biology, Yunnan Education Department; \\ ${ }^{3}$ Key Laboratory for Biochemistry and Molecular Biology of High Education in Yunnan Province, \\ Yunnan University, Kunming, Yunnan 650091; ${ }^{4}$ Department of Neurosurgery, \\ Pu'er City People's Hospital, Pu'er, Yunnan 66500, P.R. China
}

Received April 3, 2018; Accepted September 27, 2018

DOI: $10.3892 / o r .2018 .6785$

\begin{abstract}
The prognosis of patients with colorectal cancer (CRC) remains poor owing to diagnosis typically occurring at advanced stages of the disease. The understanding of the molecular regulatory signatures of CRC may lead to the identification of biomarkers for the early detection, prevention and clinical intervention of CRC. Epidemiological studies have indicated that cyclooxygenase-1 (COX-1) serves an active function in colon carcinogenesis. However, the molecular mechanism underlying COX-1 regulation in CRC remains unknown. In the present study, COX-1 was identified to be markedly upregulated in colorectal tissues of patients with CRC, and in the CRC cell lines HCT116 and HT29. To determine the function of COX-1 in cancer development, short hairpin RNA knockdown of COX-1 was employed in HCT116 and HT29 CRC cells in the present study. The results demonstrated that silencing of COX-1 depolarized the mitochondrial membrane potential, inhibited adenosine triphosphate production, induced the generation of intracellular reactive oxygen species and triggered caspase-dependent mitochondrial apoptosis. Furthermore, depletion of COX-1 suppressed anti-apoptotic B-cell lymphoma 2 and enhanced pro-apoptotic Bcl-2-associated X protein expression by inhibiting the p65 subunit phosphorylation of nuclear factor $\kappa \mathrm{B}(\mathrm{NF}-\kappa \mathrm{B})$. Taken
\end{abstract}

Correspondence to: Professor Qinghua Cui, Laboratory of Biochemistry and Molecular Biology, School of Life Sciences, Yunnan University, 2 Cuihu North Road, Kunming, Yunnan 650091, P.R. China

E-mail: cuiqinghua@ynu.edu.cn

*Contributed equally

Key words: cyclooxygenase-1, colorectal cancer, cell apoptosis, nuclear factor $\mathrm{\kappa B}$ together, the results of the present study indicated that COX-1 inhibition significantly triggered cell death by destroying the mitochondrial function that is associated with deactivation of the NF- $\kappa \mathrm{B}$ signaling pathway. These results suggest COX-1 as a potential anticancer target in CRC.

\section{Introduction}

Cancer is one of the leading causes of mortality globally, causing $\sim 8$ million instances of mortality and 13 million new cases annually (1). Colorectal cancer (CRC) is the third most common non-cutaneous malignancy, and is responsible for a marked proportion of cancer morbidity and mortality, particularly in developed countries (2). In recent years, the mortality rate of CRC has increased rapidly in China and ranks fourth among mortality caused by malignant tumors (3). CRC is typically diagnosed at advanced stages; surgery combined with chemotherapy and radiotherapy is currently the most effective approach for treatment, but the 5-year survival rate of patients with CRC has decreased to $\sim 8 \%$ with poor prognosis (4). Thus, understanding the molecular mechanisms underlying CRC development may provide insights into a novel clinical therapy strategy.

Evidence from experimental, epidemiological and clinical studies indicate that aspirin or non-steroidal antiinflammatory drugs (NSAIDs) may decrease the risk of CRC markedly through cyclooxygenase (COX) inhibition. Two isoforms of COX, identified as COX-1 and COX-2, have $\sim 60 \%$ amino acid sequence homology and catalyze the same reactions. However, they are encoded by distinct genes and differ in their tissue distribution (5). COX-2 is overexpressed in sporadic colorectal adenomas and carcinomas, compared with normal mucosa (6). It has been identified that targeting COX-2 successfully prevented CRC. That COX-2 is the only $\mathrm{COX}$ isoform involved in colorectal tumorigenesis has been challenged in a number of studies. It is widely accepted that a low dose of aspirin (between 80 and $100 \mathrm{mg}$ ) decreases the incidence and mortality of CRC primarily by targeting COX-1 
rather than COX-2 (7). Genetic knockout of COX-1 in mice markedly decreased intestinal polyposis (8). Upregulation of COX-1 expression protected intestinal stem cells from DNA damage in the early phase of intestinal tumorigenesis (9). The chemopreventive activity of 6-C-(E-phenylethenyl)-naringenin suppresses CRC growth by inhibiting COX-1 expression (10). Thus, these studies indicate that COX-1 serves an important function in colorectal carcinogenesis.

Apoptosis is a highly regulated and controlled process of programmed cell death in organism development and tissue homeostasis to remove infected cells, and thus maintain internal environment stability. Under pathological conditions, normal cells may lose their ability to undergo apoptosis, leading to uncontrolled cell growth and autoimmune diseases. Insufficient apoptosis may also lead to uncontrolled cell proliferation followed by tumorigenesis. One of the characteristics of tumor cells is the capability to evade apoptosis regulated by the balance of pro- and anti-apoptotic factors through the extrinsic or mitochondrial pathway (11). A complex interplay between mitochondrial proteins, such as the B-cell lymphoma 2 (Bcl-2) family proteins, serve essential functions in apoptosis. Anti-apoptotic $\mathrm{Bcl}-2$ and pro-apoptotic proteins Bcl-2-associated $\mathrm{X}$ protein (Bax) dimerized to control mitochondrial membrane permeabilization and mitochondrial membrane potential (MMP or $\Delta \Psi_{\mathrm{m}}$ ). The equilibrium between Bcl-2 and Bax determines the cell's fate to undergo apoptosis or cell survival (12). Therefore, understanding the function of apoptosis in tumors and exploiting the targets for anticancer drugs by controlling apoptosis in cancer cells has value in cancer therapy.

Nuclear factor $\kappa \mathrm{B}(\mathrm{NF}-\kappa \mathrm{B})$ is a major transcription factor involved in a myriad of physiological and pathological scenarios, including apoptosis, proliferation, invasion, and angiogenesis (13). In mammals, there are five homologous subunits in the

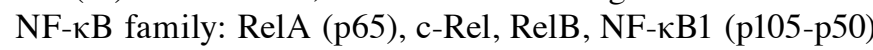

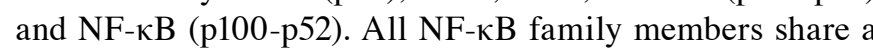
conserved Rel homology domain in their $\mathrm{N}$-terminus that is required for DNA binding, homo- and heterodimerization formation, nuclear localization and interaction with inhibitor

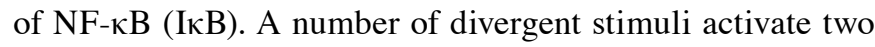
NF- $\kappa B$ pathways: The canonical and non-canonical pathways (otherwise referred to as the 'classical' and 'non-classical'). Under inactive conditions, NF- $\kappa \mathrm{B}$ is localized in the cytoplasm with three heterotrimeric complexes, including p50, $\mathrm{p} 65$, and IкB $\alpha$ in the classical NF- $\kappa \mathrm{B}$ pathway. Upon stimulation, such as by cytokines, bacterial products and tumor necrosis factor $\alpha$, the signaling pathway is activated, followed by the phosphorylation, ubiquitination and degradation of I $\kappa \mathrm{B} \alpha$ and phosphorylation of p65. Subsequently, p105-RelA is processed to $\mathrm{p} 50-\mathrm{RelA}(\mathrm{NF}-\mathrm{\kappa B})$, which translates into the nucleus and binds promoters of target genes to switch on the expression of diverse target genes involved in cell proliferation (such as c-Myc) and anti-apoptosis (such as Bcl-2) (14). The non-classical NF- $\kappa B$ pathway is activated through I $\mathrm{KB}$ kinase $\alpha$, and p100-RelB is processed into p52-RelB heterodimers, which translates into the nucleus to bind the promoter of

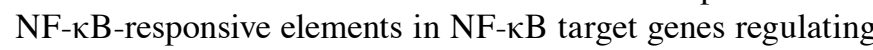
lymphoid organogenesis and maintaining the malignant phenotype in certain types of cancer (15). The activation of the two pathways relies on the inducible phosphorylation-inhibitory

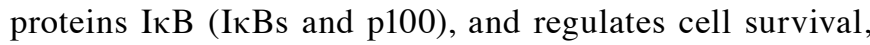
death and carcinogenesis. It has been identified that COX-2 promotes angiogenesis in aggressive forms of CRC induced by the non-classical NF- $\mathrm{BB}$ pathway (16), and overexpression of COX-2 increases the expression of Bcl-2 to inhibit apoptosis, which appears to be a key pathway in the survival of cancer cells. To the best of our knowledge, the association between $\mathrm{COX}-1$ and NF- $\mathrm{KB}$ in colorectal carcinogenesis has not been comprehensively investigated, and the underlying molecular mechanism requires elucidation.

Thus, the aim of the present study was to investigate the function of COX-1 in colorectal carcinogenesis using a short hairpin RNA (shRNA) knockdown strategy in CRC cells. The results of the present study indicated that COX-1 is required for maintaining malignant characteristics of CRC cells. Knockdown of COX-1 suppressed cell proliferation and survival, involved in mitochondrial dysfunction and triggered caspase-dependent mitochondrial apoptosis by inhibiting the p65 subunit phosphorylation of NF-kB in HCT116 and HT29 CRC cells, which indicated a potential molecular target in developing prevention or treatment of CRC.

\section{Materials and methods}

Patients and tissue samples. All colorectal tumor samples and matching normal tissues were from 14 patients with CRC (9 males and 5 females; age range, 33-68 years) at the Department of Surgery, Pu'er City People's Hospital (Pu'er, Yunnan, China), between September 2016 and November 2017. The fresh tumor tissue specimens were excised from the tumors, and their corresponding adjacent normal tissues were taken $\geq 3 \mathrm{~cm}$ from the tumor edge. All specimens were stabilized by snap-freezing immediately in cryovials, immersed in liquid nitrogen and stored at $-80^{\circ} \mathrm{C}$ until analysis.

Cell lines and cell culture. The human embryonic kidney epithelial cell line 293T, the human CRC cell lines Caco2, Colo205, SW480, HT29 and HCT116, and the normal intestinal epithelial cell FHC were obtained from the Biochemistry and Molecular Biology Laboratory of Yunnan University (Yunnan, China). Cells were cultured in high-glucose Dulbecco's modified Eagle's medium (Gibco; Thermo Fisher Scientific, Inc., Waltham, MA, USA) supplemented with $10 \%(\mathrm{v} / \mathrm{v})$ fetal bovine serum (FBS; BI Biological Industries, Wentworthville, Australia) and 1\% (v/v) antibiotics (100 mg/l streptomycin, $100 \mathrm{U} / \mathrm{ml}$ penicillin; HyClone; GE Healthcare Life Sciences, Logan UT, USA) in a cell incubator at $37^{\circ} \mathrm{C}$ with an humidified atmosphere containing $5 \% \mathrm{CO}_{2}$. Cell numbers were determined using a cell counting chamber.

Virus packaging and cellular stable transfection with shRNAs. A total of four shRNAs were used to target the COX-1 gene and were cloned into pLKO.1-puro-based lentiviral vectors (pLKO.1-puro-COX-1) synthesized by Sigma-Aldrich; Merck KGaA (Darmstadt, Germany). The COX-1 target sequences are listed in Table I. The vector pLKO.1-puro (pLKO.1-puro) was used as a negative control (mock). Lentiviruses were created in 293T cells by transfection of packaging plasmid and envelope plasmid with X-tremeGENE ${ }^{\mathrm{TM}} \mathrm{HP}$ DNA transfection reagent (Roche Diagnostics, Indianapolis, 
Table I. shRNA targets used in the present study.

\begin{tabular}{|c|c|c|}
\hline shRNA & Clone accession number & Sequence $\left(5^{\prime}-3^{\prime}\right)$ \\
\hline shCOX-1-1 & NM_000962.2-1266s1c1 & $\begin{array}{l}\text { CCGGCATGGAGTTCAACCATCTCTACTCGAGTAGAGATGGTTGAACT } \\
\text { CCATGTTTTTG }\end{array}$ \\
\hline shCOX-1-2 & NM_000962.2-822s1c1 & $\begin{array}{l}\text { CCGGCGGCCACATTTATGGAGACAACTCGAGTTGTCTCCATAAATGT } \\
\text { GGCCGTTTTTG }\end{array}$ \\
\hline shCOX-1-3 & NM_000962.2-225s1c1 & $\begin{array}{l}\text { CCGGGCCAGTGAATCCCTGTTGTTACTCGAGTAACAACAGGGATTCA } \\
\text { CTGGCTTTTTG }\end{array}$ \\
\hline shCOX-1-4 & NM_000962.2-564s1c1 & $\begin{array}{l}\text { CCGGCGTGAGCTATTACACTCGTATCTCGAGATACGAGTGTAATAGC } \\
\text { TCACGTTTTTG }\end{array}$ \\
\hline
\end{tabular}

shRNA, short hairpin RNA; COX-1, cyclooxygenase 1 .

IN, USA), according to the manufacturer's protocol. Viruscontaining supernatants were harvested at 24 and $48 \mathrm{~h}$, respectively, post-transfection and passed through a $0.45 \mu \mathrm{m}$ filter (Sigma-Aldrich; Merck KGaA) and used immediately or stored at $-80^{\circ} \mathrm{C}$ for future use. HCT116 and HT29 cells were infected twice with lentiviruses within $48 \mathrm{~h}$, and the stable silenced cells were selected using puromycin (Thermo Fisher Scientific, Inc.) at a final concentration of $6 \mu \mathrm{g} / \mathrm{ml}$. The protein expression level of COX-1 was determined using western blot analysis.

Western blot analysis. Cells or tissues were washed twice with ice-cold PBS and incubated on ice for $30 \mathrm{~min}$ in radioimmunoprecipitation buffer $(50 \mathrm{mM}$ Tris/HCl, $\mathrm{pH} 7.4,150 \mathrm{mM} \mathrm{NaCl}$, $0.5 \%$ sodium deoxycholate, $0.1 \%$ SDS, $1 \%$ NP-40, $2 \mathrm{mM}$ sodium EDTA; Beyotime Institute of Biotechnology, Haimen, China), supplemented with Complete ${ }^{\mathrm{TM}}$ protease inhibitor cocktail (Roche Diagnostics). The protein concentration was determined using a Bradford protein assay kit (Beijing Dingguo Changsheng Biotechnology Co., Ltd., Beijing, China). Equal amounts $(20 \mu \mathrm{g})$ of protein samples were separated by SDS-PAGE $(12.5 \%$ gel) using a standard protocol, and then transferred onto $0.22 \mu \mathrm{m}$ Immun-Blot ${ }^{\circledR}$ polyvinylidene difluoride membranes (Merck KGaA) with wet transfer electrophoresis (Bio-Rad Laboratories, Inc., Hercules, CA, USA). The membranes was blocked using $10 \%(\mathrm{w} / \mathrm{v})$ non-fat milk in PBS containing 1\% (w/v) Tween-20 (pH 7.4) at room temperature for $1 \mathrm{~h}$. Membranes were incubated with specific primary antibodies overnight on a rocker at $4^{\circ} \mathrm{C}$. Following washing with PBS containing $1 \%$ Tween-20, the membranes were incubated again for $2 \mathrm{~h}$ at room temperature with corresponding secondary antibodies. All primary antibodies were used at the dilutions specified by the manufacturers' protocols and secondary antibodies were used at 1:2,000 dilutions. The protein-antibody complexes were visualized using an Enhanced Chemiluminescence detection kit (Thermo Fisher Scientific, Inc.) with a chemiluminescence instrument (Tanon Science and Technology Co., Ltd., Shanghai, China). Each immunoblot depicted is representative of at least three similar independent experiments. The protein expression of each band was quantified by densitometric analysis using ImageJ software (version 1.52a; National Institutes of Health, Bethesda, MD, USA).
Antibodies. The primary antibodies for the detection of COX-1 (69kDa; cat.no.C0159) and COX-2 (72 kDa; cat.no.C0160) were purchased from Anbo Biotechnology Co., Ltd. (San Francisco, CA, USA). Anti-phospho-IкB $\alpha$ (36 kDa; cat. no. ab133462), anti-Bax (20 kDa; cat. no. ab32503), anti-voltage-dependent anion channel 2 (32 kDa; cat. no. ab47104) and anti-cleaved caspase-3 (17 kDa; cat. no. ab2302) were purchased from Abcam (Cambridge, UK). Anti-phospho-p65 (65 kDa; cat. no. 3033) and anti-c-Myc (63 kDa; cat. no. 5605) were purchased from Cell Signaling Technology (Danvers, MA, USA). Anti-Bcl-2 (26 kDa; cat. no. 551097) and anti-cyclin $\mathrm{D}_{1}$ (36 kDa; cat. no. 554180) were purchased from BD Biosciences (San Jose, CA, USA). Other primary antibodies against IкB $\alpha$ (34 kDa; cat. no. AF1282), p65 (65 kDa; cat. no. AF1234), cytochrome $c(15 \mathrm{kDa}$; cat. no. AC908), caspase-9 (47 kDa; cat. no. AC062), cleaved caspase-9 (37 kDa; cat. no. AC062), caspase-3 (35 kDa; cat. no. AC030), poly(ADP-ribose) polymerase (PARP; $116 \mathrm{kDa}$; cat. no. AF1657), cleaved PARP (89 kDa; cat. no. AF1567), cyclin $\mathrm{E}_{2}$ (47 kDa; cat. no. AF2494) and GAPDH (36 kDa; cat. no. AF0006) were purchased from Beyotime Institute of Biotechnology. The secondary antibodies used were horseradish peroxidase (HRP)-labeled goat anti-rabbit immunoglobulin $\mathrm{G}(\mathrm{IgG})$ [heavy and light chains $(\mathrm{H}+\mathrm{L})]$ (cat. no. A0208) or HRP-labeled goat anti-mouse IgG (H+L) (cat. no. A0216) (both Beyotime Institute of Biotechnology).

Analysis of apoptotic cells using Annexin V/propidium iodide (PI) dual staining. The analysis of apoptosis-mediated cell death of tumor cells was performed using a double-staining method with a fluorescein isothiocyanate (FITC)-labeled Annexin V and PI Apoptosis Detection kit (Beyotime Institute of Biotechnology), according to the manufacturer's protocol. Briefly, cell pellets were resuspended in $400 \mu \mathrm{l}$ binding buffer [10 mM 4-(2-hydroxyethyl)-1-piperazineethanesulfonic acid/ $\mathrm{NaOH}, 140 \mathrm{mM} \mathrm{NaCl}$ and $2.5 \mathrm{mM} \mathrm{CaCl}_{2}$ at $\left.\mathrm{pH} 7.4\right]$ at room temperature for $5 \mathrm{~min}$, stained with FITC-conjugated Annexin V and PI, and incubated at $4^{\circ} \mathrm{C}$ for $20 \mathrm{~min}$ in the dark. Fluorescence intensities were analyzed using an epifluorescence microscope at a magnification of x20 (Leica DMI8; Leica Microsystems GmbH, Wetzlar, Germany). The Annexin V-positive/PI-negative cells were recognized as 
early apoptotic cells, the Annexin V-positive/PI-positive cells were recognized as late apoptotic cells and the Annexin V-negative/PI-negative cells were recognized as viable cells. Three independent experiments were performed with three replicates per experiment.

Cell cycle analysis by flow cytometry. The distribution of various phases of the cell cycle $\left(G_{0} / G_{1}, S\right.$ and $\left.G_{2} / M\right)$ was determined by quantification of the DNA content of cells stained with PI solution (containing $50 \mu \mathrm{g} / \mathrm{ml}$ PI, $0.2 \%$ Triton X-100 and $100 \mu \mathrm{g} / \mathrm{ml}$ RNase A). Briefly, cells were harvested and fixed with ice-cold $70 \%$ ethanol for $30 \mathrm{~min}$ at $4^{\circ} \mathrm{C}$, then incubated with PI solution at $37^{\circ} \mathrm{C}$ for $45 \mathrm{~min}$. The cell cycle profiles were analyzed by flow cytometry (BD Biosciences).

Cell viability. The cell viability was measured by the CellTiter 96 ${ }^{\circledR}$ AQueous One Solution Cell Proliferation assay kit (Promega Corporation, Madison, WI, USA), according to the manufacturer's protocol, for various durations $(0,24,48,96$ and $144 \mathrm{~h}$ ). In brief, $40 \mu \mathrm{l}$ MTT solution was added to each well (containing 800 cells), followed by incubation at $37^{\circ} \mathrm{C}$ for $4 \mathrm{~h}$. The optical density was determined at a wavelength of $490 \mathrm{~nm}$ using a microplate reader (Bio-Rad Laboratories, Inc.). Experiments were performed in triplicate.

Determination of adenosine triphosphate (ATP). The production of ATP was determined using a luciferin/luciferase assay with an ATP assay kit (Beyotime Institute of Biotechnology), according to the manufacturer's protocol. Briefly, the cells were collected and permeabilized prior to the addition of ATP lysis buffer, and incubated on ice for $30 \mathrm{~min}$ to complete lysis. The cell lysates were centrifuged at $12,000 \mathrm{x}$ g for $10 \mathrm{~min}$ at $4^{\circ} \mathrm{C}$, and luminescence was measured using a Pi-102 fluorescence luminometer (Hygiena, Camarillo, CA, USA) immediately following mixing. The content of the cellular ATP level was calculated using the ATP standard curve. ATP content was normalized to protein concentration.

MMP assay. Breakdown of the MMP was monitored using a JC-1 Mitochondrial Membrane Potential assay kit (Beyotime Institute of Biotechnology). The cells were incubated with freshly prepared $\mathrm{JC}-1$ solution $(10 \mathrm{mg} / \mathrm{ml}$ in culture medium) for $20 \mathrm{~min}$ at $37^{\circ} \mathrm{C}$ under $5 \% \mathrm{CO}_{2}$ in the dark, and fluorescence was quantified by flow cytometry (BD Biosciences). In healthy mitochondria with normal MMP, JC-1 forms aggregates that emit red fluorescence (excitation/emission, 490/530 nm). However, in the apoptotic and necrotic cells with the loss of MMP, JC-1 does not aggregate and remains in the monomeric form that emits green fluorescence. Therefore, the increase in green florescence was due to the loss of MMP.

Detection of intracellular ROS levels. The Reactive Oxygen Species assay kit (Beyotime Institute of Biotechnology) was used to determine the accumulation of intracellular ROS, according to the manufacturer's protocol. Briefly, cells were loaded with $10 \mu \mathrm{m} \mathrm{2}$ ',7'-dichlorodihydrofluorescein diacetate at $37^{\circ} \mathrm{C}$ for $30 \mathrm{~min}$ in the dark, followed by three washes in PBS, and were resuspended in $300 \mu \mathrm{l}$ PBS and filtered. The fluorescence intensity of the resulting $2^{\prime}, 7^{\prime}$-dichlorofluorescein was determined using flow cytometry (BD Biosciences).
Pyrrolidinedithiocarbamate (PDTC) assay. To validate the association between NF- $\mathrm{B}$ and $\mathrm{COX}-1$, the specific inhibitor of NF- $\kappa \mathrm{B}$, PDTC, was dissolved in PBS. Cells $\left(1.5 \times 10^{5}\right)$ were incubated with 50 or $100 \mu \mathrm{M}$ PDTC for $48 \mathrm{~h}$, and the protein expression of $\mathrm{I} \kappa \mathrm{B} \alpha$, phospho-I $\kappa \mathrm{B} \alpha$, total p65, phospho-p65 and COX-1 was determined by western blot analysis.

Co-immunoprecipitation (co-IP) assay. The co-IP assay was performed using Protein $\mathrm{A}+\mathrm{G}$-agarose beads (Beyotime Institute of Biotechnology), according to the manufacturer's protocol. Briefly, HCT116 or HT29 cells were collected and incubated on ice for $30 \mathrm{~min}$ in $300 \mu \mathrm{l}$ native lysis buffer and centrifuged at $12,000 \mathrm{x}$ g for $15 \mathrm{~min}$ at $4^{\circ} \mathrm{C}$. A $40 \mu \mathrm{l}$ volume of supernatant was used as input and the remainder of the supernatant was precleared by mixing with $1 \mu \mathrm{g}$ normal $\mathrm{IgG}$ and $30 \mu \mathrm{l}$ Protein $\mathrm{A}+\mathrm{G}$-agarose beads at $4^{\circ} \mathrm{C}$ for $4 \mathrm{~h}$. The beads were pelleted and the supernatant was retained for co-IP by incubation with $3 \mu \mathrm{g}$ anti-COX-1 antibody $(1.5 \mathrm{mg} / \mathrm{ml}$; cat. no. ab695; Abcam) at $4^{\circ} \mathrm{C}$ overnight, or with $3 \mu \mathrm{g} \mathrm{IgG}$ ( $1 \mathrm{mg} / \mathrm{ml}$; cat. no. A7028; Beyotime Institute of Biotechnology) as the negative control. Then, Protein $\mathrm{A}+\mathrm{G}$-agarose beads were added to above mixture for $4 \mathrm{~h}$ at $4^{\circ} \mathrm{C}$. The beads were collected and washed with ice-cold PBS five times, and boiled at $95^{\circ} \mathrm{C}$ for $5 \mathrm{~min}$ in $60 \mu \mathrm{l} 1 \mathrm{X}$ loading buffer. Western blotting was performed to detect p65, phospho-p65 and COX-1.

Statistical analysis. Results are presented as the mean \pm standard error of the mean obtained from at least three independent experiments. Statistical significance was determined by one-way analysis of variance with Dunnett's analysis using SPSS software (version 19.0; IBM Corp., Armonk, NY, USA). $\mathrm{P}<0.05$ was considered to indicate a statistically significant difference.

\section{Results}

COX-1 is required for maintaining CRC malignant characteristics. To investigate whether human COX-1 is associated with the tumorigenic properties of $\mathrm{CRC}$, the expression of COX-1 in colorectal tumor samples and matching normal tissues was investigated. The results indicated that COX-1 was more markedly expressed in CRC tissues compared with in normal tissues (Fig. 1A). COX-1 expression was determined to be significantly increased in the 14 colorectal tumor tissues (Fig. 1B). Next, the expression of COX-1 in five CRC cell lines (Caco2, Colo205, SW480, HT29 and HCT116) and a normal intestinal epithelial cell FHC was investigated. Consistent with the results in tissues, the CRC cells expressed increased COX-1 levels compared with FHC cells (Fig. 1C), particularly in HT29 and HCT116 cells, which were therefore selected for shRNA interference for subsequent assays. Together, these results indicate that COX-1 serves an important function in maintaining the malignant characteristics in CRC.

COX-1 knockdown suppresses proliferation of HCT116 and HT29 CRC cells. To investigate whether the decreased expression of COX-1 affects the development of CRC tumors, COX-1 was depleted in HCT116 and HT29 CRC cells using four specific shRNAs (termed shCOX-1-1, shCOX-1-2, shCOX-1-3 and shCOX-1-4, respectively) and negative control (plasmid 

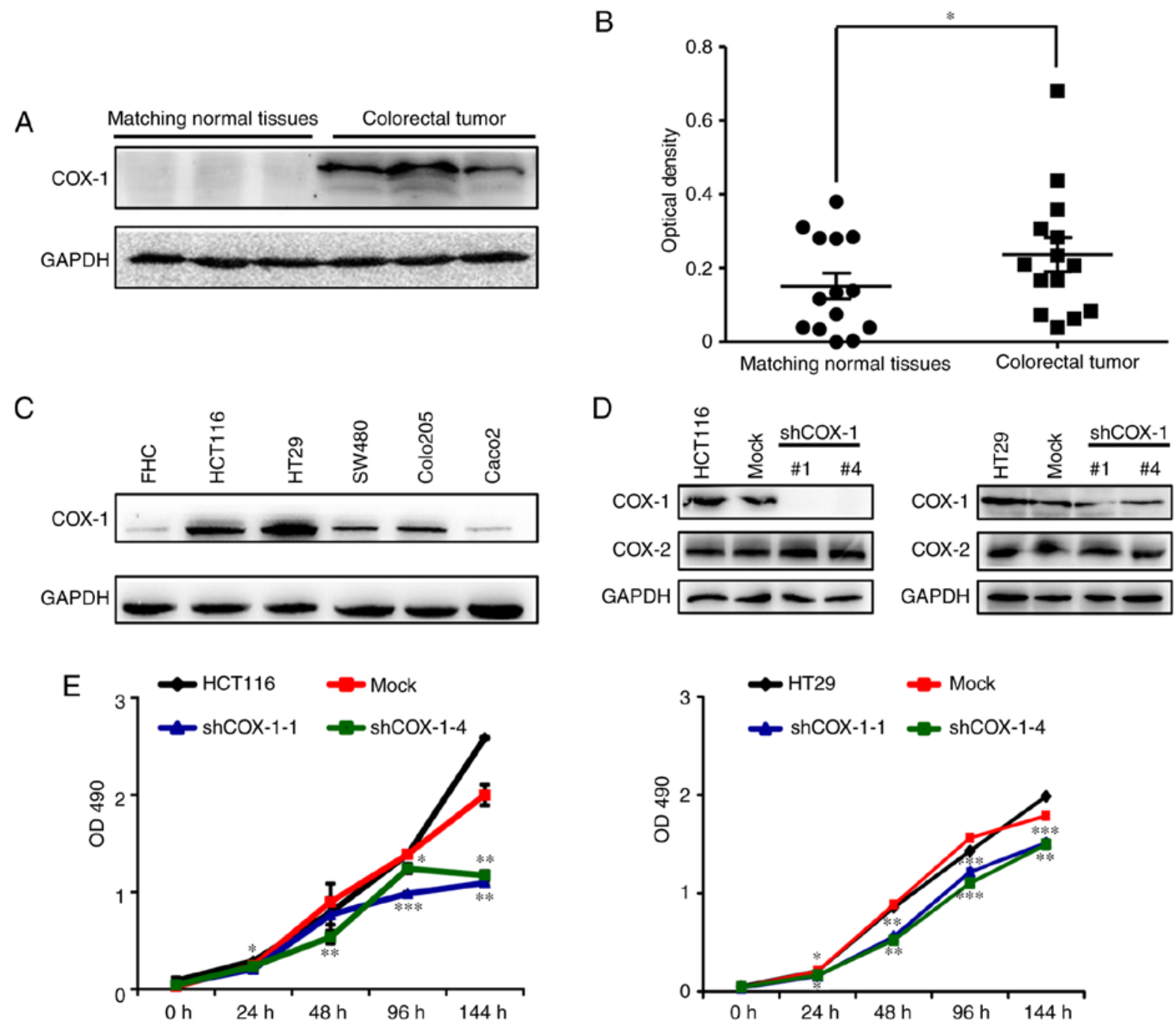

Figure 1. COX-1 is required for maintaining colorectal cancer malignant characteristics. (A) Western bolt analysis of COX-1 expression in human CRC tissues and their corresponding adjacent normal tissue. (B) COX-1 expression in human colorectal tumor tissues and adjacent normal control tissues from 14 patients with CRC. "P<0.05. (C) Expression of COX-1 in four CRC cell lines and the normal intestinal epithelial cell FHC determined by western blotting. (D) Expression of COX-1 and COX-2 in COX-1-knockdown HCT116 and HT29 CRC cells determined by western blotting. (E) MTT assay of cell proliferation. ${ }^{*} \mathrm{P}<0.05,{ }^{* *} \mathrm{P}<0.01,{ }^{* * *} \mathrm{P}<0.001$ vs. mock. COX-1, cyclooxygenase 1; CRC, colorectal cancer; OD, optical density; sh, short hairpin RNA.

without COX-1 shRNA, termed mock) to establish the stable shCOX-1-knockdown HCT116 and HT29 cell lines with lentivirus particles. It was identified that $\mathrm{COX}-1$ was markedly downregulated by shCOX-1-1 and shCOX-1-4 as determined by western blotting in HCT116 and HT29 cells. However, the expression of COX-2 protein was unchanged (Fig. 1D). It confirmed that the shRNAs specifically targeted the COX-1 in HCT116 and HT29 CRC cells. It was investigated whether COX-1 inhibition was able to decrease the viability of HCT116 and HT29 CRC cells. An MTT assay was used to quantify cell proliferation at $0,24,48,96$ and $144 \mathrm{~h}$ after shRNA knockdown. The results indicated that COX-1 downregulation significantly inhibited the cell proliferation in the two cell lines (Fig. 1E). These observations indicated that COX-1 is required for the proliferation of HCT116 and HT29 CRC cells.

COX-1 downregulation depolarizes MMP, eliminates ATP production and increases intracellular ROS. The significant decrease in cell proliferation raised the hypothesis that depletion of COX-1 alters mitochondrial function in CRC cells, as mitochondria provide energy to support the cell proliferation. It was identified that the generation of ATP was significantly inhibited in HCT116 and HT29 CRC cells treated with shCOX-1-1 and shCOX-1-4 compared with the mock (Fig. 2A). In addition, ROS production was significantly induced in COX-1-knockdown cells (Fig. 2B and C). Mitochondrial membrane integrity by MMP was investigated using the cationic mitochondrial dye JC-1; the COX-1-knockdown CRC cells exhibited depolarization of mitochondria and loss of MMP (Fig. 2D). These results suggested that depletion of COX-1 led to mitochondrial dysfunction in CRC cells.

COX-1 downregulation halts cells in $G_{0} / G_{1}$ phase and triggers apoptosis. A significant accumulation in $\mathrm{G}_{0} / \mathrm{G}_{1}$ phase and a reciprocal decrease in $\mathrm{S}$ phase were observed in shCOX-1-treated HCT116 and HT29 CRC cells, compared with the control. In addition, markedly decreased expression of cyclin $E_{2}$ in the COX-1-knockdown HCT116 and HT29 cells was observed (Fig. 3A and B). These results indicated that the inhibitory effect of COX-1 knockdown 
A
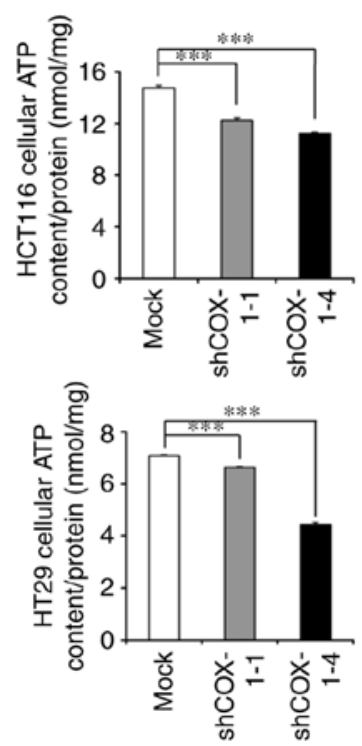

B

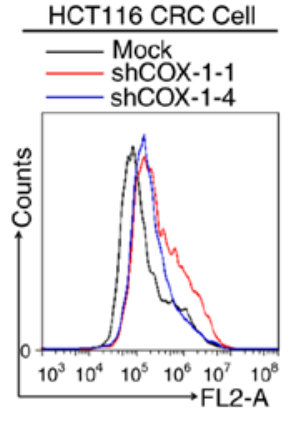

C
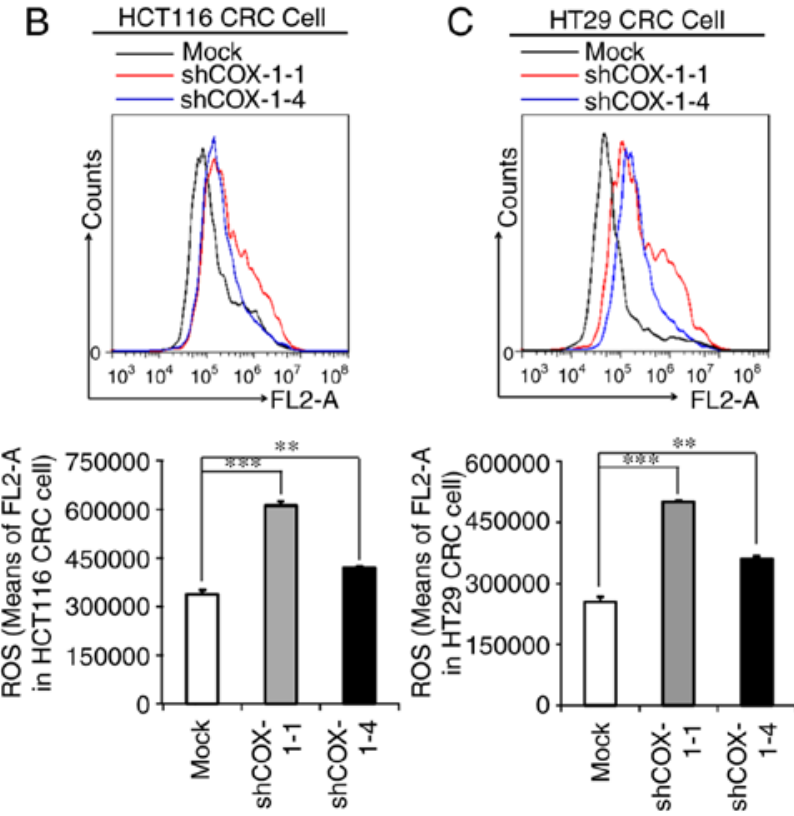
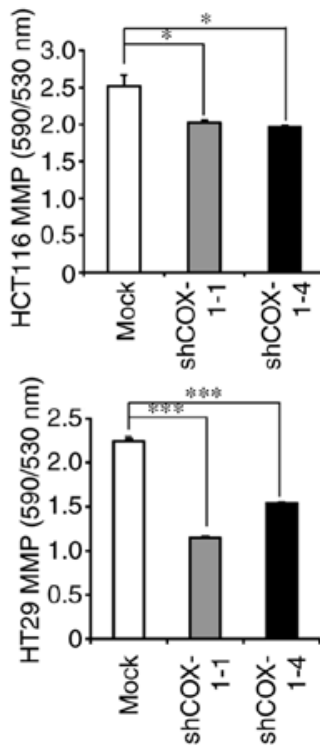

Figure 2. Effects of COX-1 downregulation on mitochondrial function in HCT116 and HT29 CRC cells. (A) Depletion of COX-1 decreased ATP generation. COX-1 knockdown increased ROS generation in (B) HCT116 and (C) HT29 CRC cells. (D) Loss of MMP in COX-1-knockdown cells. ${ }^{*}<<0.05,{ }^{* *} \mathrm{P}<0.01$, ${ }^{* * *} \mathrm{P}<0.001$. COX-1, cyclooxygenase 1; CRC, colorectal cancer; ATP, adenosine triphosphate; MMP, mitochondrial membrane potential; ROS, reactive oxygen species; sh, short hairpin RNA.
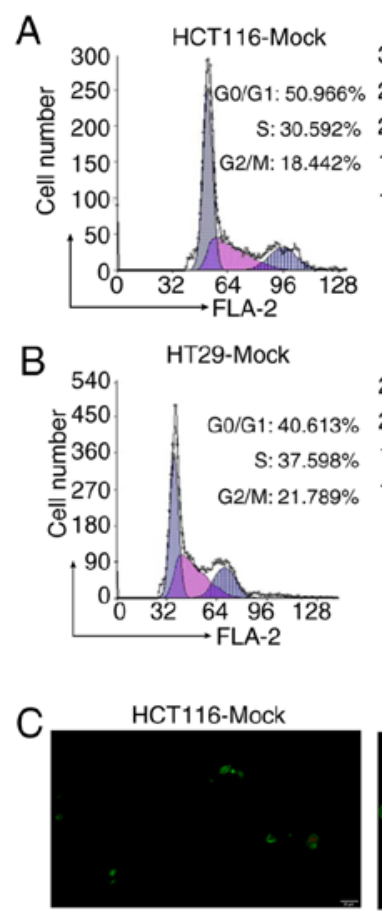

D

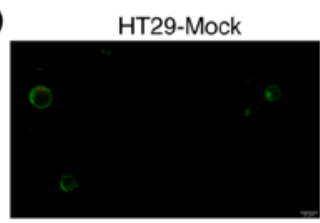

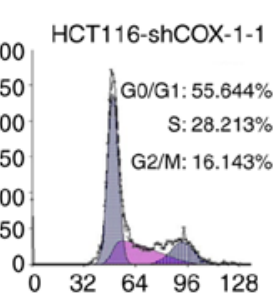

HT29-shCOX-1-1
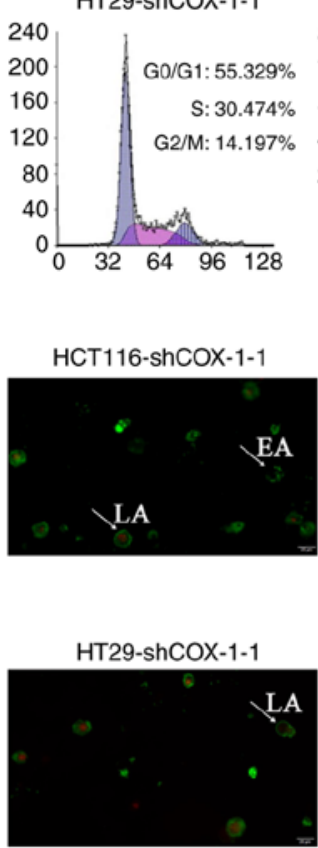
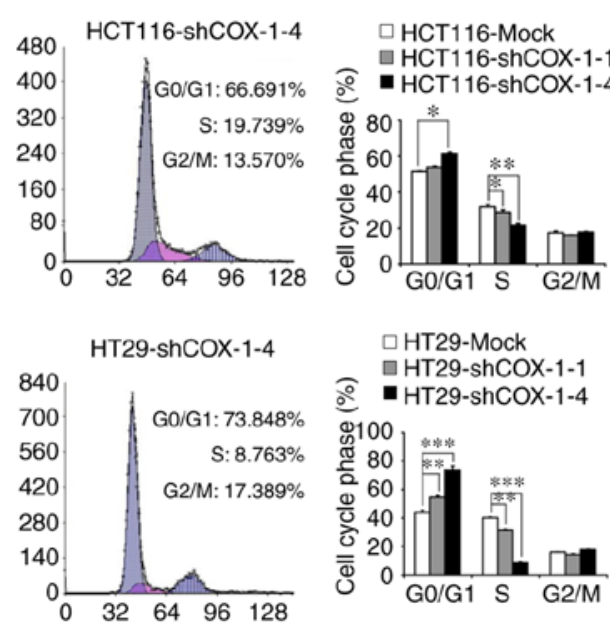

HT29-Mock

ஓ $\mathbf{m}$ HT29-shCOX-1-4
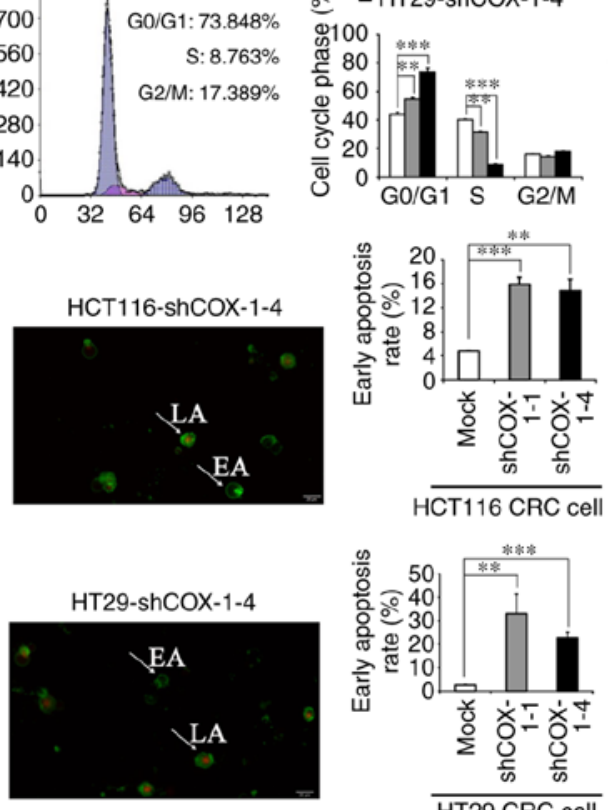
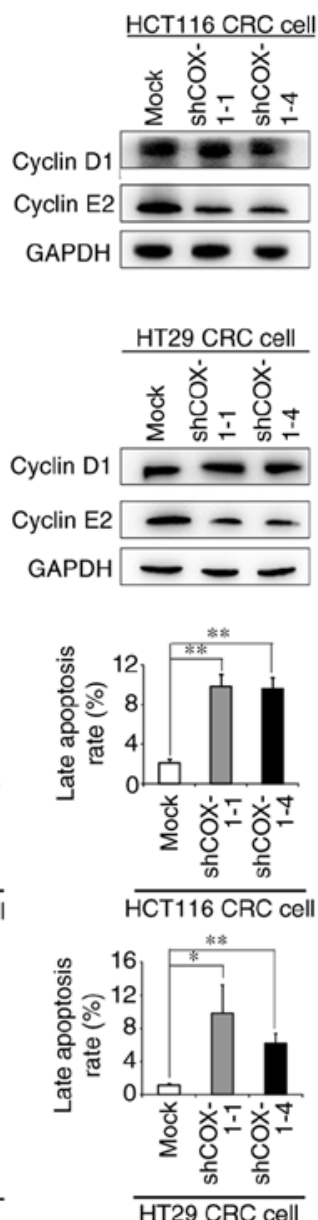

Figure 3. Depletion of COX-1 induces cell cycle arrest and triggers apoptosis in HCT116 and HT29 CRC cells. Downregulation of COX-1 induced $\mathrm{G}_{0} / \mathrm{G}_{1}$ arrest in (A) HCT116 and (B) HT29 CRC cells, as determined by flow cytometry, and expression of cell cycle-associated proteins cyclin $\mathrm{D}_{1}$ and cyclin $\mathrm{E}_{2}$ as determined by western blotting. Apoptosis assay of (C) HCT116 and (D) HT29 CRC cells with fluorescein isothiocyanate-Annexin V/propidium iodide double staining visualized under a fluorescence microscope. Representative fluorescence images analysis are presented. ${ }^{*} \mathrm{P}<0.05,{ }^{* *} \mathrm{P}<0.01,{ }^{* * *} \mathrm{P}<0.001$. Original magnification, $\mathrm{x} 20$. COX-1, cyclooxygenase 1; CRC, colorectal cancer; sh, short hairpin RNA; EA, early apoptosis; LA, late apoptosis. 
A
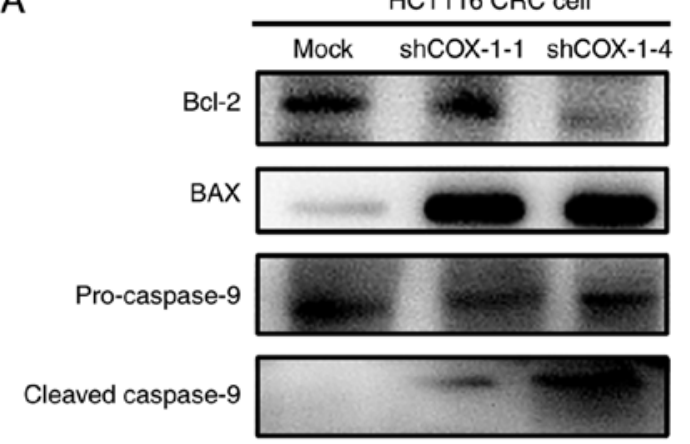

Pro-caspase-3

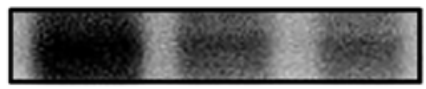

Cleaved caspase-3

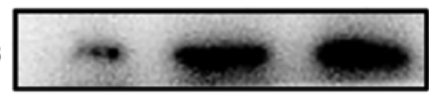

Pro-PARP

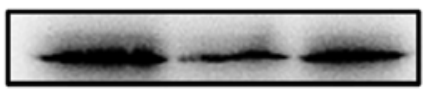

Cleaved-PARP

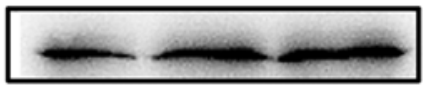

GAPDH

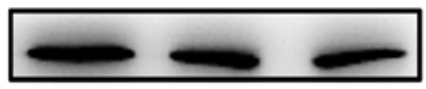

C

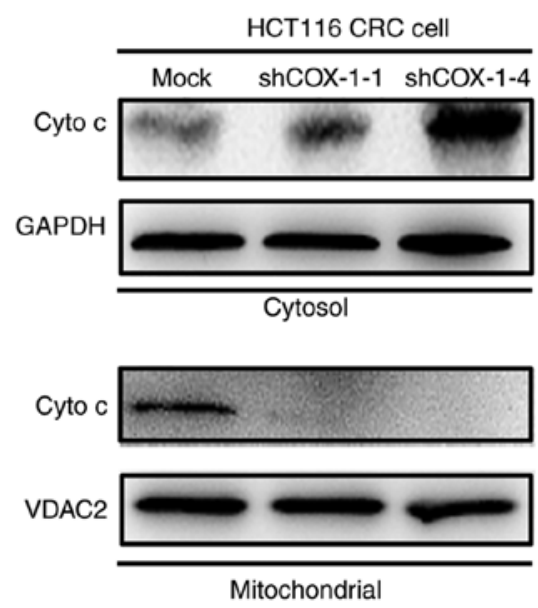

B

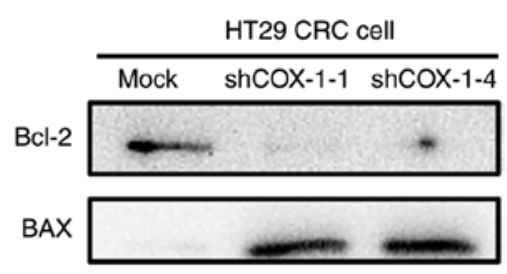

Pro-caspase-9

Cleaved caspase- 9

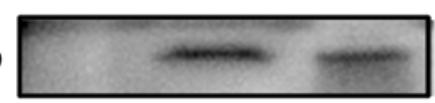

Pro-caspase-3

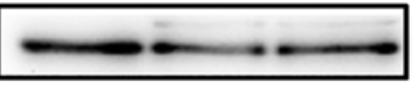

Cleaved caspase-3
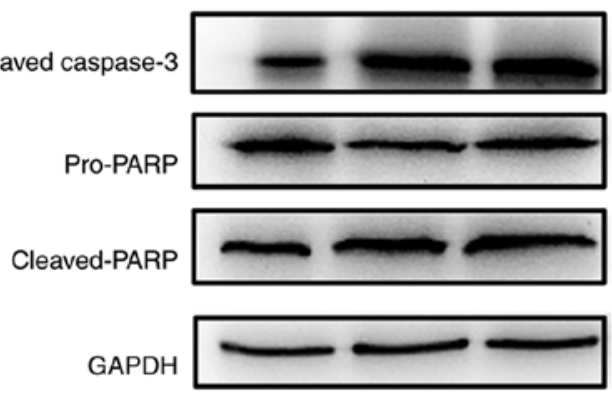

D

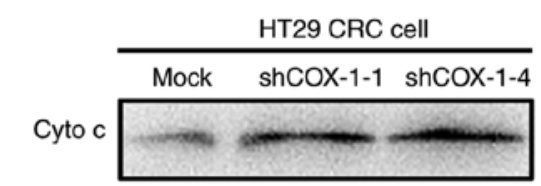

GAPDH
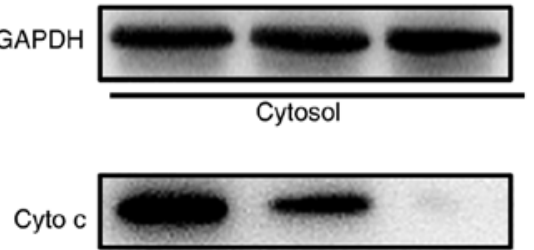

VDAC2

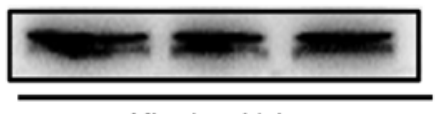

Figure 4. Downregulation of COX-1 induces apoptotic cell death via the intrinsic mitochondrial and caspase-dependent pathway. Cells were harvested and lysed for determination of the expression of apoptosis-associated proteins Bcl-2, Bax, procasapse-9, cleaved caspase-9, procasapse-3, cleaved caspase-3, pro-PARP, cleaved PARP in (A) HCT116 and (B) HT29 CRC cells, and cytosolic cytochrome $c$ and mitochondrial cytochrome $c$ in (C) HCT116 and (D) HT29 CRC cells, by western blotting. GAPDH was used as a loading control for cytosolic proteins and VDAC2 was used as a loading control for mitochondrial proteins. COX-1, cyclooxygenase 1; Bcl-2, B-cell lymphoma 2; Bax, Bcl-2-associated X protein; PARP, poly(ADP-ribose) polymerase; CRC, colorectal cancer; VDAC2, voltage-dependent anion channel 2; sh, short hairpin RNA; cyto c, cytochrome $c$.

on cell proliferation was partially due to $G_{0} / G_{1}$ phase arrest caused by the decreased expression of cyclin $\mathrm{E}_{2}$. Induction of apoptosis in COX-1-downregulated cells was investigated using Annexin V/PI dual staining using an epifluorescence microscope; the early apoptotic cells (green color) and the late apoptotic cells (green and red color) were increased in shCOX-1-treated HCT116 and HT29 cells (Fig. 3C and D). Collectively, these results indicated that cell cycle and apoptosis were involved in the proliferation mediated by shCOX-1 depletion in HCT116 and HT29 cells.

COX-1 downregulation activates caspase-dependent mitochondrial apoptosis. The aforementioned results indicated that the apoptosis triggered by downregulation of COX-1 serves an important function in HCT116 and HT29 CRC cell proliferation. Thus, the apoptotic pathway involved in COX-1-regulated cell death was investigated, focusing on initiator pro-caspase-9 and effector pro-caspase-3, as well as their substrate PARP. The western blot results indicated that depletion of COX-1 in HCT116 and HT29 cells promoted the accumulation of cleaved executioner caspases-9 and -3 , and PARP fragment, and decreased the precursor proteins pro-caspase- 9 and -3 , and full-length PARP (Fig. 4A and B). It suggested that a marked proportion of the precursors were cleaved to execute the apoptotic process following stimulation by COX-1 knockdown. In addition, it was revealed that the expression of anti-apoptotic Bcl-2 was markedly downregulated and a marked increase in pro-apoptotic Bax was observed upon COX-1 depletion 
A

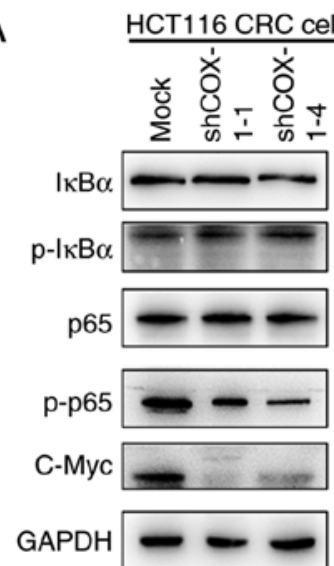

C

C

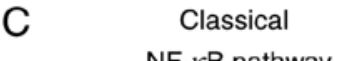

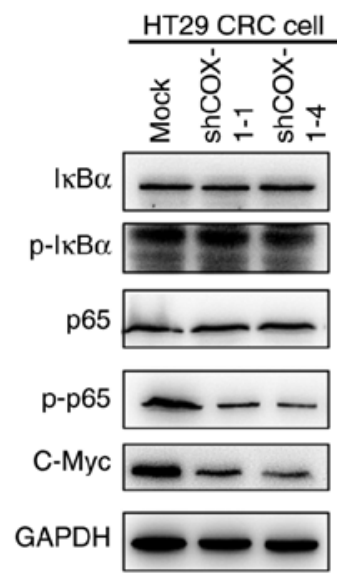

No-classical

NF-KB pathway

Proteasomal

Processing
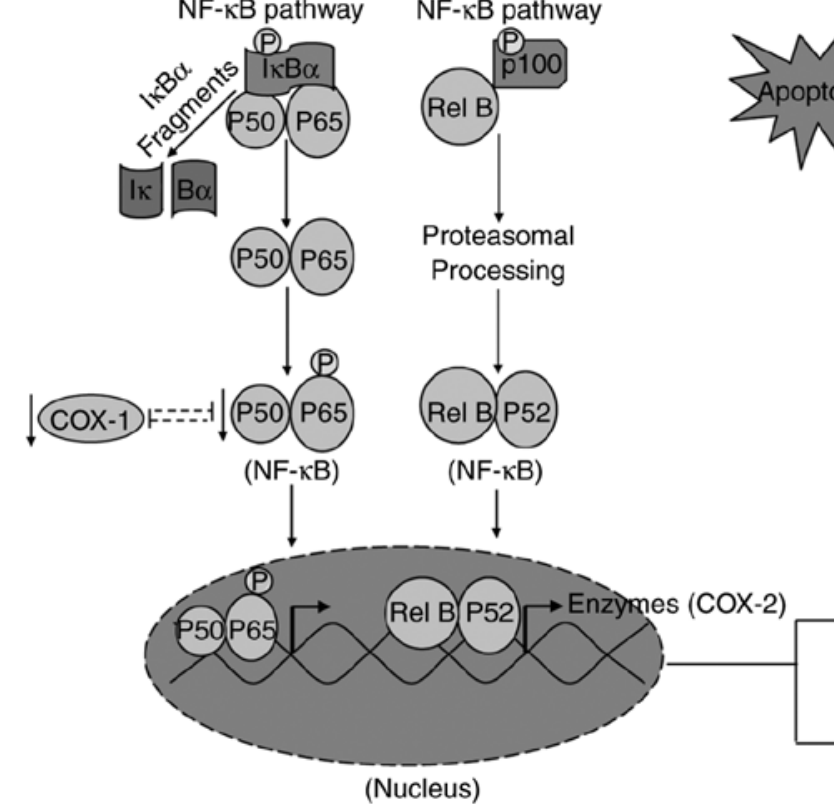

B

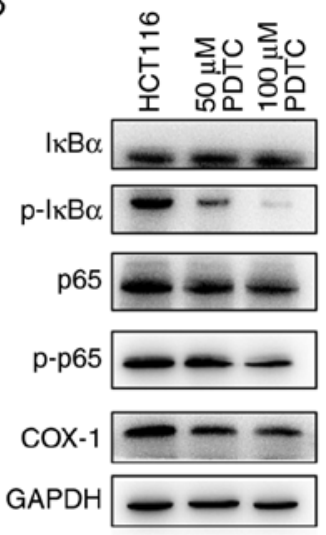

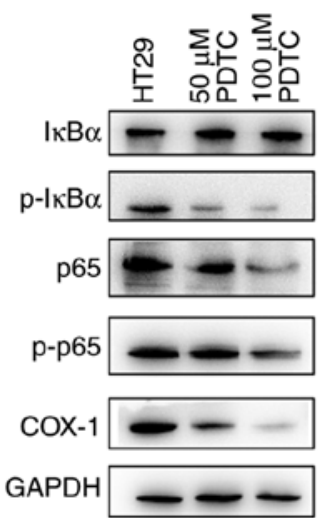

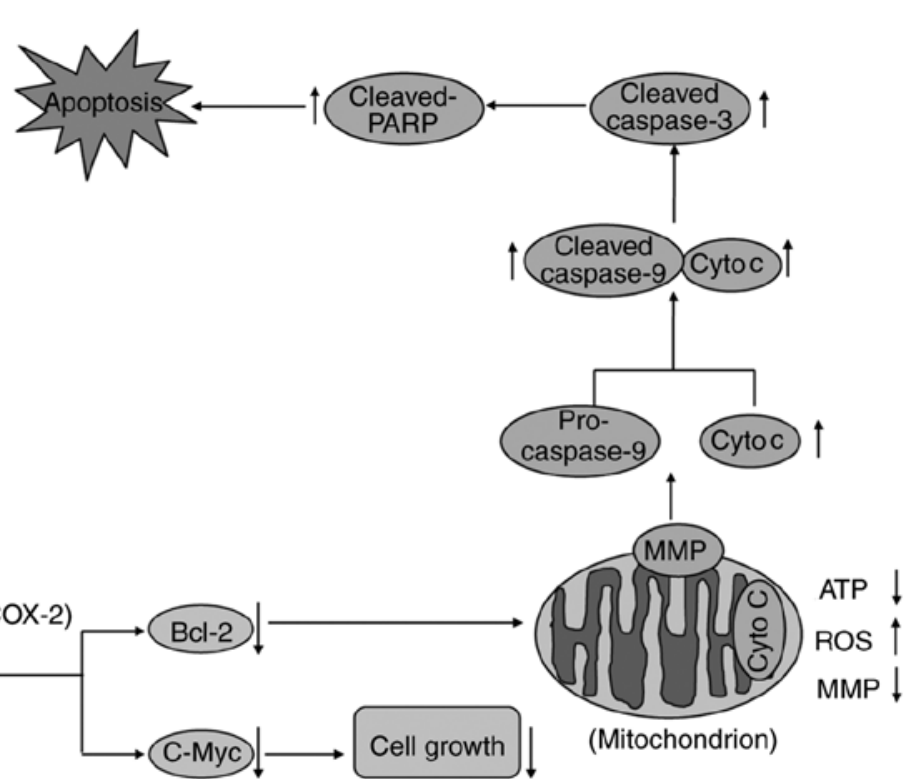

Figure 5. Depletion of COX-1 suppresses the activation of the NF- $\mathrm{kB}$ signaling pathway. (A) Immunoblot analysis of NF- $\mathrm{B}$ signaling pathway-associated genes in COX-1-knockdown HCT116 and HT29 CRC cells. (B) HCT116 and HT29 CRC cells were treated with PDTC, a p65 (NF- $\mathrm{kB}$ )-specific inhibitor. (C) Schematic diagram indicating potential molecular mechanisms by which knockdown of COX-1 induces apoptosis in HCT116 and HT29 CRC cells. COX-1,

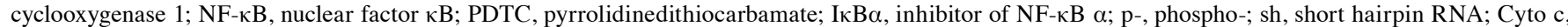
cytochrome $c$; ROS, reactive oxygen species; ATP, adenosine triphosphate; MMP, mitochondrial membrane potential; Bcl-2, B-cell lymphoma 2; PARP, poly(ADP-ribose) polymerase.

which usually regulated the intrinsic apoptosis through the mitochondrial pathway (Fig. 4A and B). Thus, the Bax/Bcl-2 ratio was increased, indicating that mitochondrial apoptosis was induced upon COX-1 depletion. Bcl-2 antagonizes the dimerization of Bax to prevent the loss of MMP and block the release of cytochrome $c$ from the mitochondria to the cytosol. The release of cytochrome $c$ initiates the caspase cascade cleavage as a hallmark of the mitochondrial apoptotic pathway. Consistent with this, an increase in cytosolic cytochrome $c$ and a decrease in mitochondria cytochrome $c$ were observed (Fig. 4C and D). Taken together, the results revealed that depletion of COX-1 in HCT116 and HT29 cells led to mitochondrial dysfunction with the depolarized MMP, less ATP and excessive ROS stress. At the molecular level, the $\mathrm{Bax} / \mathrm{Bcl}-2$ ratio was increased, the release of cytochrome $c$ was initiated and the caspase cascade was activated, which ultimately resulted in apoptotic cell death.
Depletion of COX-1 in CRC cells induces apoptosis via the $N F-\kappa B$ signaling pathway. Considering that the NF- $\kappa \mathrm{B}$ signaling pathway is involved in a variety of cellular processes including apoptosis, proliferation, cell survival and invasion, combined with the fact that the anti-apoptotic gene Bcl-2 is the downstream target of the NF- $\kappa \mathrm{B}$ signaling pathway, we hypothesized that the effects of COX-1 knockdown on cell proliferation may be associated with the activation of the NF- $\mathrm{KB}$ signaling pathway. It is well-known that the p65 subunit of NF- $\kappa B$ is phosphorylated and translocates to nucleus when the NF- $\kappa$ B signaling pathway was activated. In the present study, the phosphorylation of the p65 subunit was suppressed in shCOX-1-transfected HCT116 and HT29 CRC cells compared with the control, whereas the total p65 level was stable following COX-1 depletion (Fig. 5A). By contrast, the expression of the oncogene c-Myc (Fig. 5A) and Bcl-2 were downregulated (Fig. 4A and B) in COX-1-knockdown cells 
compared with the control. These results indicated that COX-1 downregulation induced apoptosis and decreased cell proliferation, in part, via inhibiting the phosphorylation of the p65 subunit of NF- $\kappa B$. Furthermore, a specific inhibitor of $N F-\kappa B$, PDTC, was used to validate the association between NF- $\mathrm{NB}$ and COX-1. It was identified that the phosphorylated I $\kappa \mathrm{B} \alpha$ subunit, total p65 and phosphorylated p65 were markedly inhibited by PDTC; however, the expression of total $\mathrm{I} \kappa \mathrm{B} \alpha$ was not altered with $48 \mathrm{~h}$ of treatment with either 50 or $100 \mu \mathrm{M}$ PDTC. The expression of COX-1 was also markedly decreased following PDTC treatment (Fig. 5B). These results suggested that knockdown of COX-1 suppressed the phosphorylation of p65 subunit of NF- $\kappa \mathrm{B}$, which in turn downregulated the downstream Bcl-2 and c-Myc. However, the results of the co-immunoprecipitation assay indicated that there was no direct interaction between COX-1 and the phospho-p65/p65 subunit of NF- $\mathrm{B}$ (data not shown). We therefore hypothesized that there are intermediate signaling proteins between $\mathrm{COX}-1$ and $\mathrm{NF}-\kappa \mathrm{B}$.

\section{Discussion}

The incidence of CRC has increased as a result of the change in diets and lifestyles in society. Surgery combined with chemotherapy and radiotherapy is a useful treatment for advanced-stage (III and IV) CRC. However, chemoresistance is the major obstacle hindering effective therapy of patients with advanced CRC, with poor survival of patients and frequent relapse. Therefore, searching for highly effective antitumor targets and novel therapeutic anticancer agents is an urgent requirement. COX-2 has been intensively investigated as an essential factor involved in the development of various types of cancer; however, COX-1 has emerged as exhibiting an important function in tumor progression, particularly in colon carcinogenesis. Wu et al (17) indicted that treatment of colon cancer cells with a COX-1 inhibitor decreased cell proliferation, and induced alterations in morphological and biochemical characteristics associated with cell cycle arrest and macroautophagy. Li et al (10) identified that COX-1 is required for the maintenance of malignant characteristics of colon cancer cells or tumor promoter-induced transformation of pre-neoplastic cells, and the specific COX-1 inhibitor as a potential preventive agent against CRC. Chulada et al (8) observed that knockout of COX-1 markedly decreased the incidence of polyposis in Min mice to suppress colorectal carcinogenesis. Clinical studies indicated that inhibiting COX-1 and COX-2 with conventional NSAIDs to decrease the number of intestinal polyps in patients with familial adenomatous polyposis is more effective than with COX-2-selective inhibitors only (18). However, the precise molecular mechanism underlying COX-1 regulation in CRC remains to be determined. The results of the present study indicated that COX-1 is upregulated in CRC clinical tissues and cell lines, which indicated COX-1 may be required for maintaining malignant characteristics of CRC cells. To investigate this hypothesis, a DNA vector-based COX-1-specific shRNA approach was used to knock down COX-1 to determine the biological consequences in HCT116 and HT29 CRC cells. An MTT assay was used to determine the inhibition of proliferation in COX-1-knockdown CRC cells, and flow cytometric analysis revealed $G_{0} / G_{1}$ arrest, which indicated COX-1-mediated cell proliferation in CRC.
Mitochondrial metabolism was identified to participate in various biological processes. Mitochondrial DNA has been used as a promising strategy for cancer therapy and a number of physical and chemical stimuli causing mitochondrial dysfunction have been reported (19). In healthy cells, the inner mitochondrial membrane is nearly impermeable to all ions, which contribute to the robust formation of an electrochemical gradient resulting in the MMP required for ATP synthesis. However, the long-lasting opening of the mitochondrial permeability transition pore will lead to permanent MMP dissipation and cell death (20). In the present study, it was demonstrated that depletion of COX-1 depolarized the MMP, increased the accumulation of ROS and diminished ATP. ROS typically promote mitochondrial dysfunction and serve an upstream function in the inhibition of proliferation and mitochondria-mediated apoptosis (21). Accumulation of intracellular ROS altered the mitochondrial membrane integrity and depolarized MMP, which caused mitochondrial swelling and increased permeability of the mitochondrial membrane, led to cytochrome $c$ leaks from the perforated mitochondria and induced mitochondrial intrinsic apoptosis (also called the mitochondria-mediated pathway of apoptosis). The leaked cytochrome $c$ leads to formation of an apoptosome which activates pro-caspase- 9 and initiates the chain reaction of the classical caspase cascade, defined as caspase dependent-apoptosis (22). COX-1 knockdown in the present study induced caspase-dependent apoptosis with upregulation of cytosolic cytochrome $c$, caspase- 9 and -3 activation, and PARP cleavage, along with downregulation of mitochondria cytochrome $c$, which indicated that cytochrome $c$ leaks from the mitochondria to the cytosol. In addition, Bcl-2 family members are key factors in mitochondrial function, cell cycle and apoptosis $(23,24)$. In the present study, it was also revealed that downregulation of COX-1 in CRC cells significantly decreased anti-apoptotic Bcl-2 expression and increased pro-apoptotic Bax expression, with deleterious mitochondrial function. It is generally accepted that the imbalance between the expression of Bcl-2 and Bax proteins leads to permeabilization of the mitochondrial outer membrane, followed by release of cytochrome $c$ and subsequent cell death (25). These alterations indicated that COX-1 induced mitochondrial apoptosis by mediating Bcl-2 family members in CRC cells. Taken together, the results of the present study shed new light on the association between COX-1 and cell death in CRC.

In $\mathrm{CRC}, \mathrm{NF}-\kappa \mathrm{B}$ was constitutively activated; aberrant $\mathrm{NF}-\kappa \mathrm{B}$ activation is involved in enhanced proliferation (regulating c-Myc), evasion of apoptosis (regulating Bcl-2 and Bax), invasion (regulating vascular endothelial growth factor) and angiogenesis (regulating cytokines and chemokines) by regulating the expression of diverse target genes (14). It is suggested that a series of pharmacological NF- $\kappa \mathrm{B}$ inhibitors may be potential anticancer agents in cancer therapy (26). Communication between COX-2 and upstream NF- $\mathrm{BB}$ has been suggested previously, with results indicating that $\mathrm{COX}-2$ is increased in CRC to promote angiogenesis induced by $\mathrm{NF}-\kappa \mathrm{B}$ (16). The interaction between COX-2 and NF- $\kappa \mathrm{B}$ occurs directly; the COX-2 promoter contains a consensus binding sequence (-223/-214, GGGACTACCC) for NF- $\mathrm{B}$ (27). COX-2 is one of the target genes for non-classical $N F-\kappa B$ pathway that primarily targets p52-RelB dimers translocated into the 
nucleus and activated the target genes for regulating lymphoid organogenesis and maintaining the malignant phenotype in certain types of cancer (14). However, COX-1 lacks the corresponding promoter elements for $\mathrm{NF}-\kappa \mathrm{B}$ (28). In the present study, the specific inhibition of COX-1 by shRNA led to downregulation of phosphorylation of the p65 subunit of $\mathrm{NF}-\kappa \mathrm{B}$. Furthermore, phosphorylation of $\mathrm{p} 65$, as well as COX-1, was markedly inhibited by the NF- $\kappa \mathrm{B}$ inhibitor PDTC. These results indicated that COX-1 activated NF- $\kappa \mathrm{B}$ through phosphorylation of its subunit $\mathrm{p} 65$, and could also respond to $\mathrm{NF}-\kappa \mathrm{B}$ signaling as a feedback loop. However, co-immunoprecipitation assays were performed, and the results indicated that there was no direct interaction between COX-1 and the phospho-p65/p65 subunit of NF- $\mathrm{BB}$. We therefore hypothesized that certain intermediate signaling proteins must exist between COX-1 and NF- $\mathrm{NB}$. A previous study indicated that epidermal growth factor (EGF) receptor (EGFR) signaling pathways were partial inhibitors in EGF-induced neoplastic transformation by downregulation of COX-1 in CRC (10). In addition, constitutive EGFR signaling activates $\mathrm{NF}-\kappa \mathrm{B}$ through the I $\kappa \mathrm{B} \alpha$ phosphorylation on $\mathrm{Ser}^{32} / \mathrm{Ser}^{36}$, thereby affecting the translocation of p65 subunit signal to the nucleus in prostate cancer cells (29). Therefore, we hypothesized that the EGFR/NF- $\kappa \mathrm{B}$ signaling pathway may be the intermediate signaling pathway between $\mathrm{COX}-1$ and $\mathrm{NF}-\kappa \mathrm{B}$; however, this requires verification. We also hypothesize that the different responses to $\mathrm{NF}-\kappa \mathrm{B}$ of $\mathrm{COX}-1$ and $\mathrm{COX}-2$ are based on their differences in the promoter region; $\mathrm{COX}-2$ is the target gene of non-classical NF- $\mathrm{B}$ pathway through $\mathrm{p} 52$, and COX-1 may be the target gene of the classical NF- $\mathrm{B}$ pathway involved in regulating cell survival and carcinogenesis through p65.

In summary, the results of the present study identified an association between COX-1 and CRC. COX-1 was upregulated in CRC tissues and cells, and deletion of COX-1 from CRC cells inhibited proliferation with $\mathrm{G}_{0} / \mathrm{G}_{1}$ arrest and triggered the caspase-dependent apoptotic response to mitochondrial dysfunction. The cell proliferation assay, flow cytometry analysis of cell cycle and apoptotic analysis indicated that COX-1 inhibition could significantly decrease the viability of HCT116 and HT29 CRC cells. Therefore, we hypothesize that depletion of COX-1 in HCT116 and HT29 CRC cells will suppress tumor growth in mice, which requires validation using xenograft mice models. In addition, the results of the present study revealed that COX-1 downregulation could deactivate the NF- $\mathrm{B}$ signaling pathway by inhibiting the phosphorylation of the p65 subunit, that in turn suppresses the expression of its downstream anti-apoptosis gene $\mathrm{Bcl}-2$, and decreases the $\mathrm{Bcl}-2 / \mathrm{Bax}$ ratio to promote the release of cytochrome $c$ from the intermembrane space of mitochondria into the cytosol, together with the cleavage of caspase- 9 and-3, and PARP. Finally, all these responses induced by COX-1 knockdown contributed to the inhibition of cell proliferation. The present study provides an improved understanding of the diverse pathways including apoptosis and mitochondrial metabolism for the involvement of COX-1 in CRC, indicating the potential for COX-1 as a target for CRC therapy.

\section{Acknowledgements}

Not applicable.

\section{Funding}

The present study was financially supported by the National Natural Science Foundation of China (grant nos. 81760507, 81360310, 81360175 and 81660583), Key Project of Yunnan Education Department (grant no. ZD2015002) and Natural Scientific Research Foundation of Yunnan Education Department (grant no. 2015Z019).

\section{Availability of data and materials}

The datasets used during the present study are available from the corresponding author upon reasonable request.

\section{Authors' contributions}

LD, HG, ZL and QC conceived and designed the research, collected and assembled the data, and wrote the manuscript. LD, HG and ZL performed the experiments. LD and QC reviewed and edited the manuscript. QL, WW, JR, MY and JL analyzed the data. All authors have read and approved the content of the manuscript and agree to be accountable for all aspects of the research in ensuring that the accuracy or integrity of any part of the work are appropriately investigated and resolved.

\section{Ethics approval and consent to participate}

Written informed consent for the present study use of tissue specimens was obtained from all patients, and ethical approval was approved from the Ethics Committees of Pu'er City People's Hospital (Pu'er, China) and School of Medicine in Yunnan University (Kunming China).

\section{Patient consent for publication}

Not applicable.

\section{Competing interests}

The authors declare that they have no competing interests.

\section{References}

1. Jemal A, Bray F, Center MM, Ferlay J, Ward E and Forman D: Global cancer statistics. CA Cancer J Clin 61: 69-90, 2011.

2. Lloyd SC, Harvey NR, Hebert JR, Daguise V, Williams D and Scott DB: Racial disparities in colon cancer. Primary care endoscopy as a tool to increase screening rates among minority patients. Cancer 109: 378-385, 2007.

3. Xiang L, Wang S, Jin X, Duan W, Ding X and Zheng C: Expression of BMP2, TLR3, TLR4 and COX2 in colorectal polyps, adenoma and adenocarcinoma. Mol Med Rep 6: 973-976, 2012.

4. O'Connell JB, Maggard MA and Ko CY: Colon cancer survival rates with the new American Joint Committee on Cancer sixth edition staging. J Natl Cancer Inst 96: 1420-1425, 2004.

5. Ricciotti E and FitzGerald GA: Prostaglandins and inflammation. Arterioscler Thromb Vasc Biol 31: 986-1000, 2011.

6. Chapple KS, Cartwright EJ, Hawcroft G, Tisbury A, Bonifer C, Scott N, Windsor AC, Guillou PJ, Markham AF, Coletta PL, et al: Localization of cyclooxygenase-2 in human sporadic colorectal adenomas. Am J Pathol 156: 545-553, 2000.

7. Tsikas D, Tewes KS, Gutzki FM, Schwedhelm E, Greipel J and Frolich JC: Gas chromatographic-tandem mass spectrometric determination of acetylsalicylic acid in human plasma after oral administration of low-dose aspirin and guaimesal. J Chromatogr B Biomed Sci Appl 709: 79-88, 1998. 
8. Chulada PC, Thompson MB, Mahler JF, Doyle CM, Gaul BW, Lee C, Tiano HF, Morham SG, Smithies O and Langenbach R: Genetic disruption of Ptgs-1, as well as Ptgs-2, reduces intestinal tumorigenesis in Min mice. Cancer Res 60: 4705-4708, 2000

9. Riehl TE, George RJ, Sturmoski MA, May R, Dieckgraefe B Anant S and Houchen CW: Azoxymethane protects intestinal stem cells and reduces crypt epithelial mitosis through a COX-1-dependent mechanism. Am J Physiol Gastrointest Liver Physiol 291: G1062-G1070, 2006.

10. Li H, Zhu F, Chen H, Cheng KW, Zykova T, Oi N, Lubet RA Bode AM, Wang M and Dong Z: 6-C-(E-phenylethenyl)naringenin suppresses colorectal cancer growth by inhibiting cyclooxygenase-1. Cancer Res 74: 243-252, 2014.

11. Zahedifard M, Faraj FL, Paydar M, Yeng Looi C, Hajrezaei M, Hasanpourghadi M, Kamalidehghan B, Abdul Majid N, Mohd Ali H and Ameen Abdulla M: Synthesis, characterization and apoptotic activity of quinazolinone Schiff base derivatives toward MCF-7 cells via intrinsic and extrinsic apoptosis pathways. Sci Rep 5: 11544, 2015.

12. Martinou JC and Youle RJ: Mitochondria in apoptosis: Bcl-2 family members and mitochondrial dynamics. Dev Cell 21: 92-101, 2011.

13. Karin M: Nuclear factor-kappaB in cancer development and progression. Nature 441: 431-436, 2006.

14. Wang S, Liu Z, Wang L and Zhang X: NF-kappaB signaling pathway, inflammation and colorectal cancer. Cell Mol Immunol 6: 327-334, 2009.

15. Southern SL, Collard TJ, Urban BC, Skeen VR, Smartt HJ, Hague A, Oakley F, Townsend PA, Perkins ND, Paraskeva C and Williams AC: BAG-1 interacts with the p50-p50 homodimeric NF- $\kappa \mathrm{B}$ complex: Implications for colorectal carcinogenesis. Oncogene 31: 2761-2772, 2012.

16. Tsujii M, Kawano S, Tsuji S, Sawaoka H, Hori M and DuBois RN: Cyclooxygenase regulates angiogenesis induced by colon cancer cells. Cell 93: 705-716, 1998.

17. Wu WK, Sung JJ, Wu YC, Li HT, Yu L, Li ZJ and Cho CH: Inhibition of cyclooxygenase-1 lowers proliferation and induces macroautophagy in colon cancer cells. Biochem Biophys Res Commun 382: 79-84, 2009.
18. Dolara P, Caderni G and Tonelli F: Nimesulide, a selective anti-inflammatory cyclooxygenase-2 inhibitor, does not affect polyp number and mucosal proliferation in familial adenomatous polyposis. Scand J Gastroenterol 34: 1168, 1999.

19. Yusnita Y, Norsiah MD and Rahman AJ: Mutations in mitochondrial NADH dehydrogenase subunit $1(\mathrm{mtND})$ gene in colorectal carcinoma. Malays J Pathol 32: 103-110, 2010.

20. Kroemer G, Galluzzi L and Brenner C: Mitochondrial membrane permeabilization in cell death. Physiol Rev 87: 99-163, 2007.

21. Liang W, Cai A, Chen G, Xi H, Wu X, Cui J, Zhang K, Zhao X, Yu J, Wei B, et al: Shikonin induces mitochondria-mediated apoptosis and enhances chemotherapeutic sensitivity of gastric cancer through reactive oxygen species. Sci Rep 6: 38267, 2016.

22. Cregan SP,Dawson VL and Slack RS: Role of AIF in caspase-dependent and caspase-independent cell death. Oncogene 23: 2785-2796, 2004.

23. Fu XF, Yao K, Du X, Li Y, Yang XY, Yu M, Li MZ and Cui QH: PGC- $1 \alpha$ regulates the cell cycle through ATP and ROS in $\mathrm{CH} 1$ cells. J Zhejiang Univ Sci B 17: 136-146, 2016.

24. Du X, Fu X, Yao K, Lan Z, Xu H, Cui Q and Yang E: Bcl-2 delays cell cycle through mitochondrial ATP and ROS. Cell Cycle 16: 707-713, 2017.

25. Goldar S, Khaniani MS, Derakhshan SM and Baradaran B Molecular mechanisms of apoptosis and roles in cancer development and treatment. Asian Pac J Cancer Prev 16: 2129-2144, 2015.

26. Baud V and Karin M: Is NF-kappaB a good target for cancer therapy? Hopes and pitfalls. Nat Rev Drug Discov 8: 33-40, 2009.

27. Reddy ST, Wadleigh DJ and Herschman HR: Transcriptional regulation of the cyclooxygenase-2 gene in activated mast cells. J Biol Chem 275: 3107-3113, 2000.

28. Griswold DE and Adams JL: Constitutive cyclooxygenase (COX-1) and inducible cyclooxygenase (COX-2): Rationale for selective inhibition and progress to date. Med Res Rev 16: 181-206, 1996.

29. Shostak K and Chariot A: EGFR and NF- $\mathrm{BB}$ : Partners in cancer Trends Mol Med 21: 385-393, 2015. 